\title{
The Effect of Virtual Reality (dream creating), on Resilience of Female Elderlies
}

\begin{abstract}
Introduction: Iran's elderly population is expected to reach $26 \%$ of total population in 2050 , so their mental and physical health, needs special attention. This study aimed to investigate the effect of virtual reality (dream-creating) on resilience of female elderlies.

Methods: This quasi-experimental study was applied in pretestposttest-follow up design with control group. The data population was 250 female elderlies over 65 year old from Sari, without any heart or mental diseases, who volunteered to participate in study through virtual network announcements from December 2019 to February 2020. Based on purposive sampling, 30 of them, who received the lowest score in CD-RISC, were matched in term of their age, employment status and education, and then randomly divided in to two groups of 15 experimental and control. The virtual reality intervention including specific dream creating for each participant, was performed on experimental group, then follow up stage was applied one month later. Data were analyzed using SPSS v24 software and through ANCOVA and MANCOVA.

Results: data analysis indicated that virtual reality (dream creating) has a significant positive effect on increasing the resilience of female elderlies ( $\mathrm{p}<0 / 001, \mathrm{~F}=138 / 841)$, in addition the results was stable one month after the intervention.

Conclusion: Therefore this method has an appropriate capability for applying health promotion interventions.
\end{abstract}

Keywords: Resilience, Virtual Reality, Dream Creating, Elderly, Women

\section{Article Info}

Authors:

Dadkhah $\mathrm{S}^{1}$ 우

Ansari Shahidi $\mathrm{M}^{2 *}$ 잉

Rezaie Jamalouie $\mathrm{H}^{3}$ ॰

Rahnejat $\mathrm{AM}^{4} \bullet$

Received: 2020.10 .29

Accepted: 2020.11.18

E-Published: 2020.12.05

\footnotetext{
Affiliations

1- Ph.D student, Department of Psychology, Islamic Azad University, Najafabad Branch, Najafabad, Iran.

2- Assistant professor, Department of Psychology, Najafabad Branch, Islamic Azad University, Najafabad, Iran.

Corresponding Author: Dransarishahidi@gmail.com

3- Assistant professor, Department of Psychology, Najafabad Branch Islamic Azad University, Najafabad, Iran

4- Assistant professor, Department of Clinical Psychology, Medical Faculty, Aja University of Medical Sciences, Tehran, Iran.
}

\section{Citation Subjects:}

Aged, Thoughts, Images, Emotions, Female 
فصلنامه يرستار و يزشك در رزم / ياييز 99 / سال هشتم

\section{اثربخشى واقعيت مجازى (خلق رويا) بر تابآورى سالمندان زن}

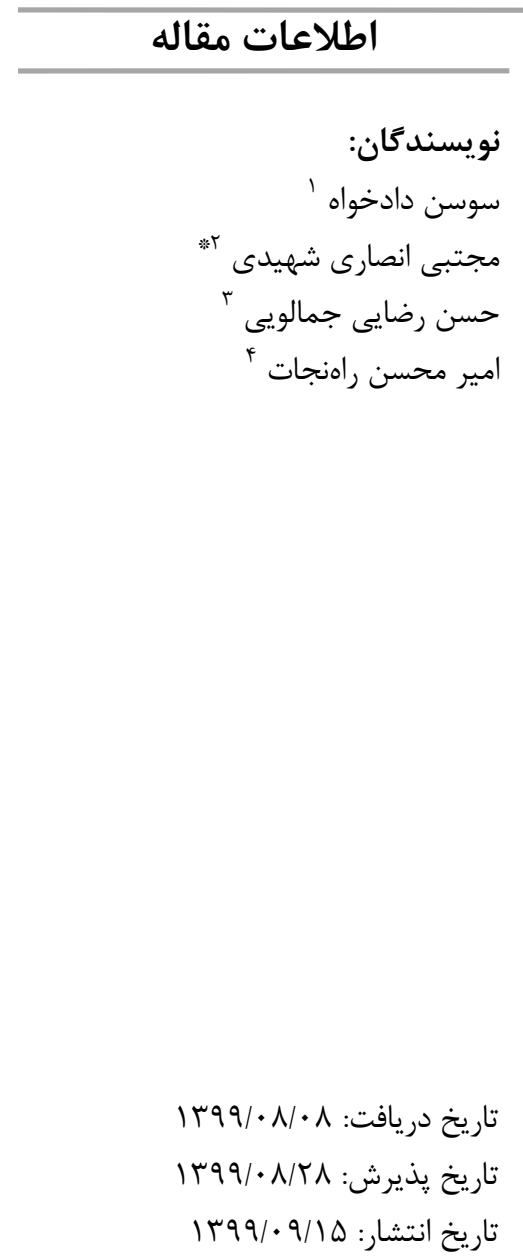

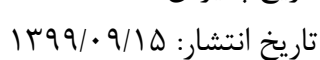

عناوين ارجاعى: "ِايدارى، تحمل، طاقت، سالخورده،

\section{جكبده}

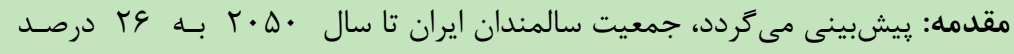

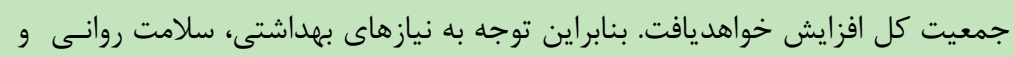

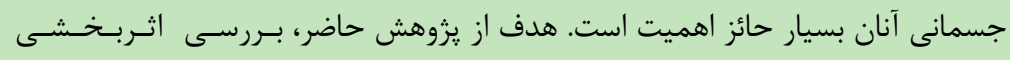

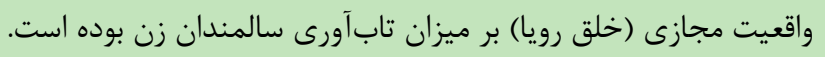

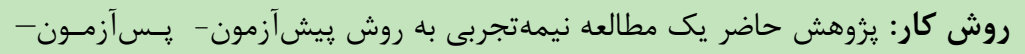

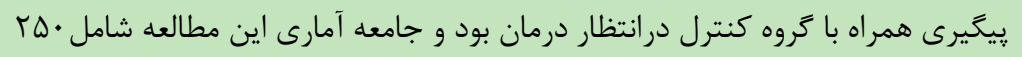

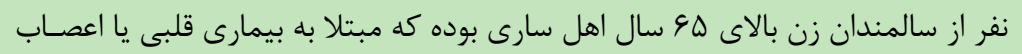

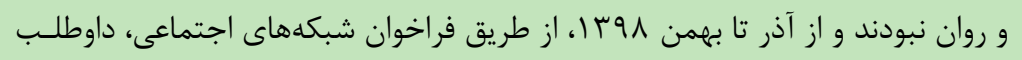

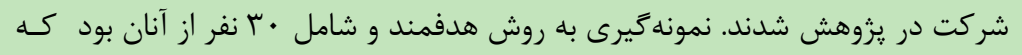

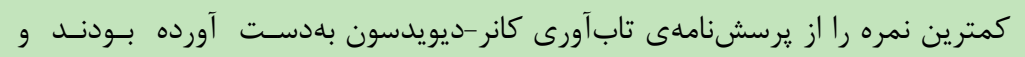

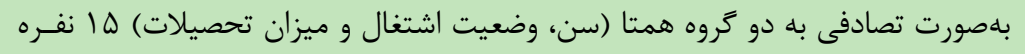

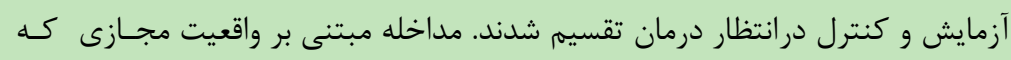

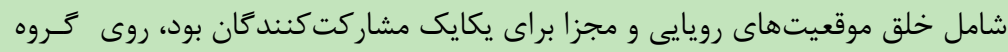

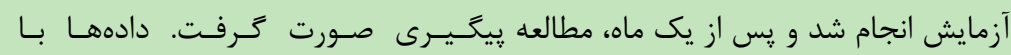

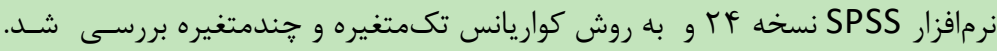

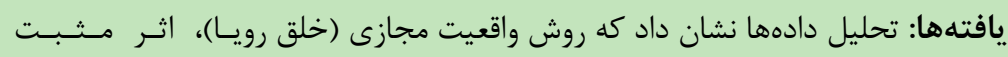

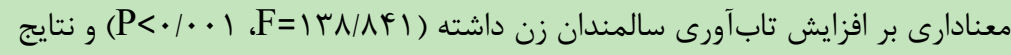

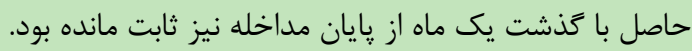

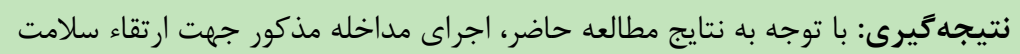
در جمعيت سالمندان پيشنهاد مىشود. وازًَان كليدى: تابآروى، واقعيت مجازى، خلق رويا، سالمند، زنان
1 - دانشجوى دكترى، كروه روانشناسى، واحد نجفآباد، دانشخاه آزاد اسلامى، نجفآباد، ايران.

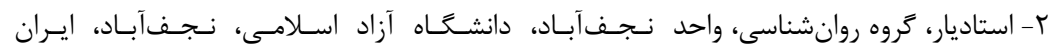

Dransarishahidi@gmail.com (نويسنده مسئول) r- استاديار، كروه روانشناسى، واحد نجف آباد، دانشعاه آزاد اسلامى، نجف آباد، ايران.

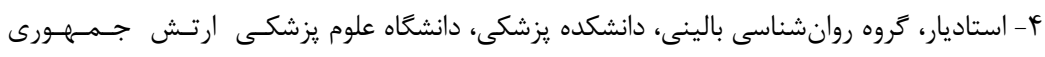
اسلامى ايران، تهران، ايران. 


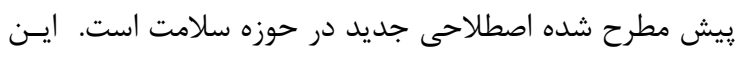

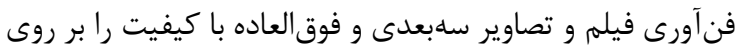

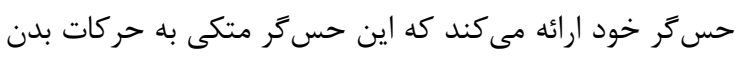
و فرامين صوتى كاربر است.

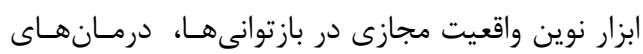

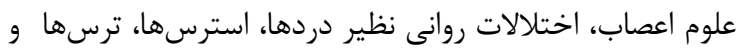

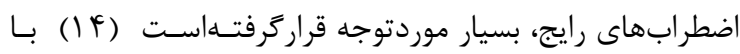
اينوجود، جنين فن آورىهايى نبايد تنها بر بيمارى و ناتوانى هاى

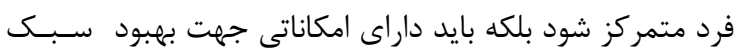

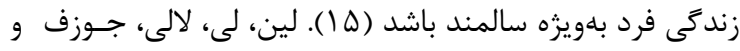

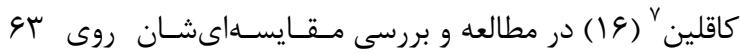

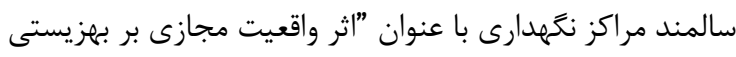

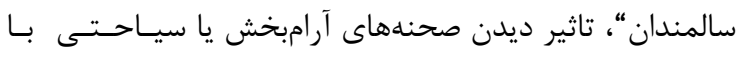

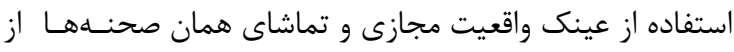

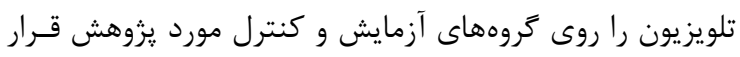

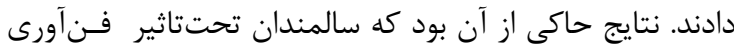

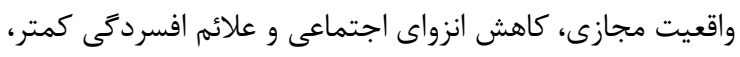

تاثير مثبت و احساس بهزيستى بيشترى را زَزارش كردند.

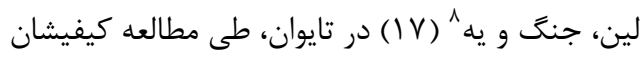
تحت عنوان ادراك معنا و ارزش با كاربرد واقعيت مجازى در در ايام

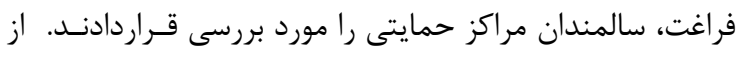

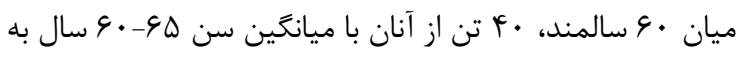

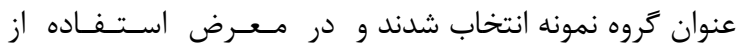

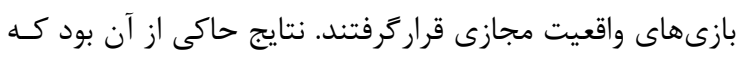

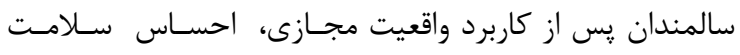

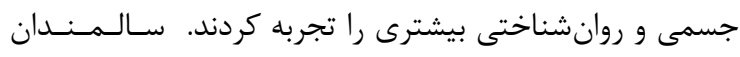

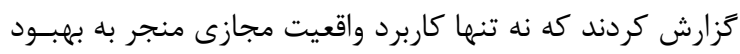

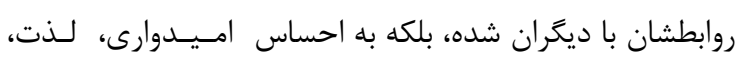

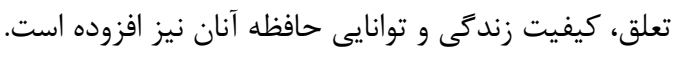

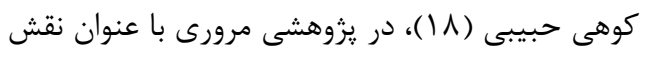

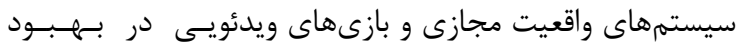

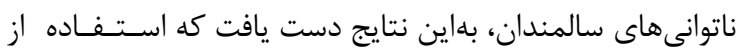

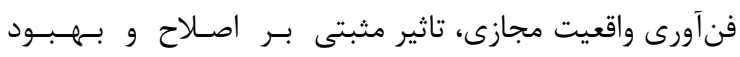

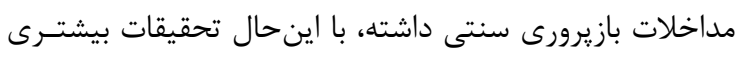

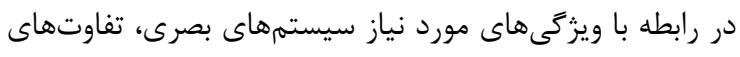

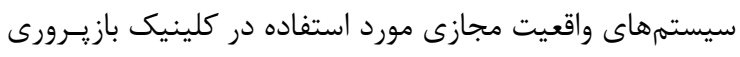

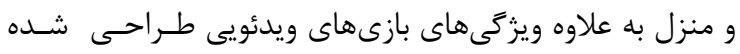

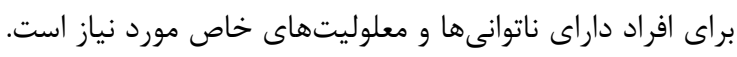

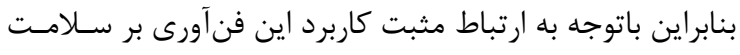

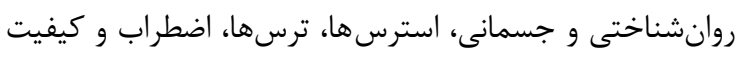

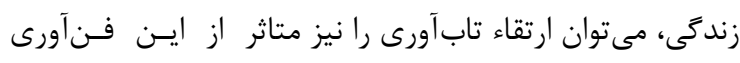

7- Lin, Lee, Lally \& Coghlin 8- Lin, Jeng \& Yeh
مقدمه

كذشت عمر و رسيدن به سنين سالمندى' براى يكايك انسانها

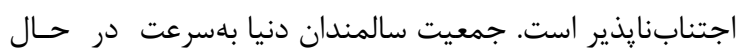

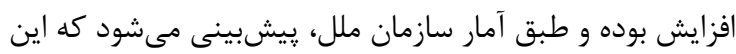

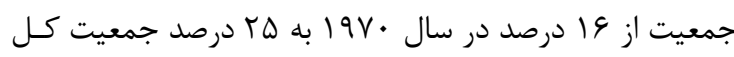

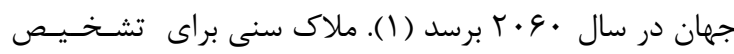

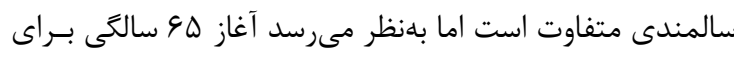

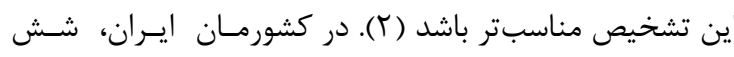

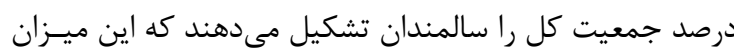

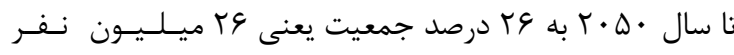

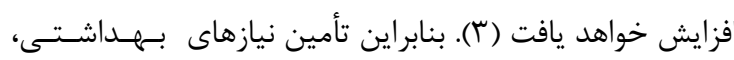

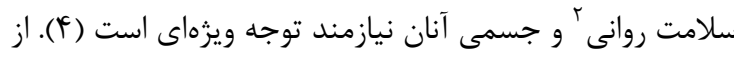

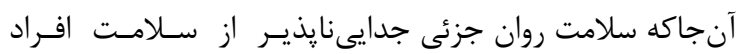

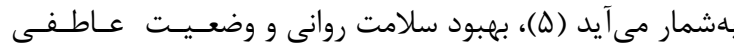

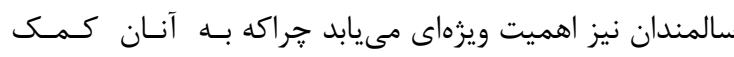

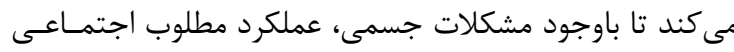

خود را حفظكنند (9).

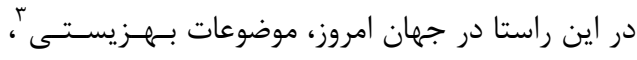

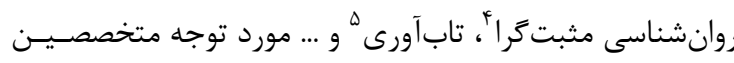

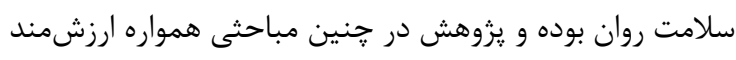

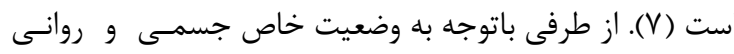

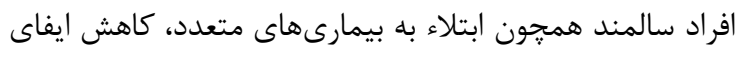
نقش جسمى و احساس سربارى در محيط خانواده يا جامعه كه

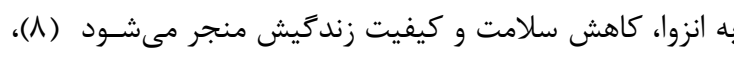

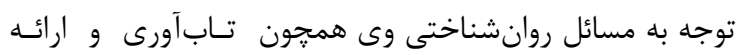
راهكارهايى جهت ارتقاء سلامت وى ضرورى است.

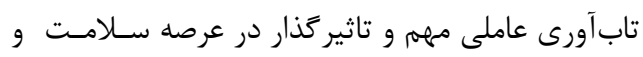

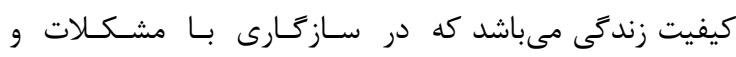

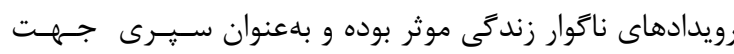

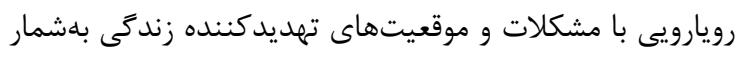

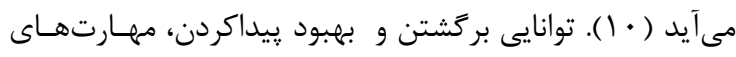

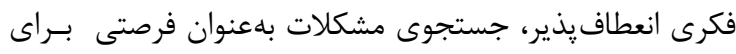

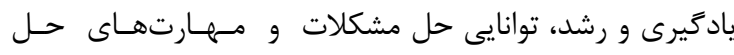

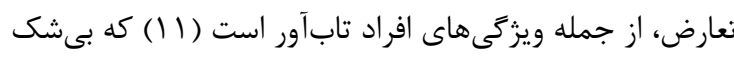
بخشى از سالمندى موفق بهشمار مى آيد (T) (I ).

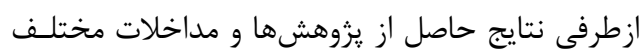

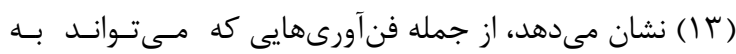

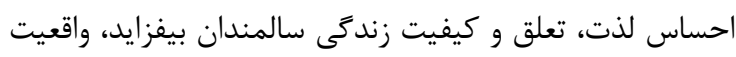

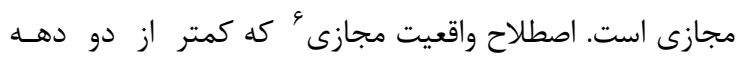

1- Elderly

2- Mental Health

3- Well-being

4- Positive Psychology

5- Resiliency

6- Virtual Reality 


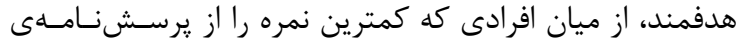

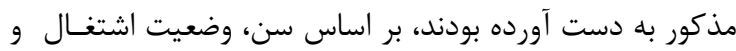

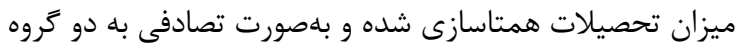

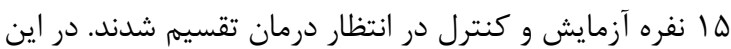

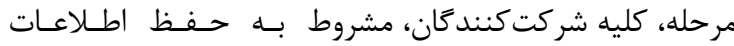

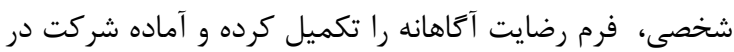

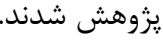

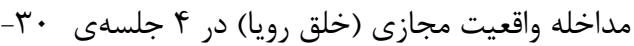

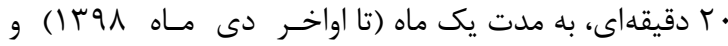

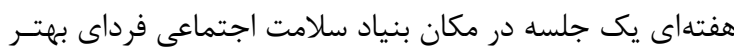

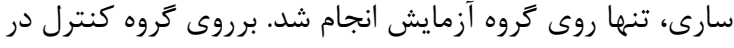

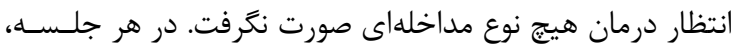

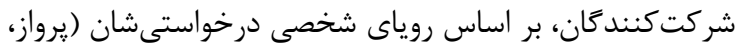

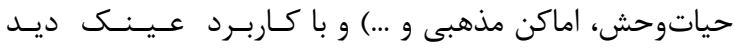

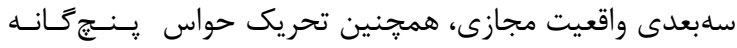

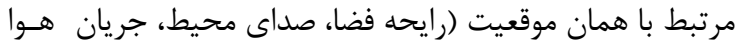

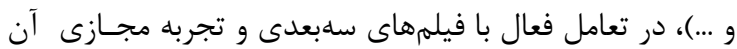

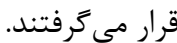

براى يزوهش حاضر، از هدست موبايلى واقعيت مجازى

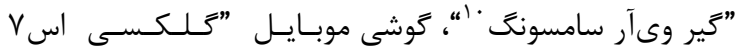

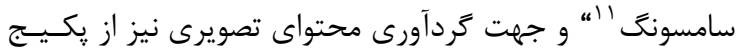

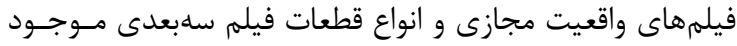

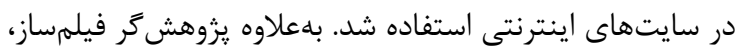

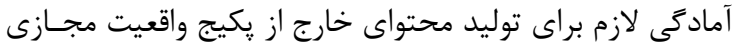

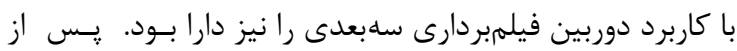

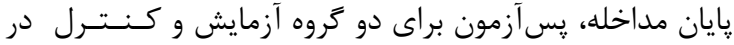

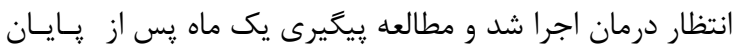

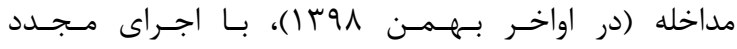

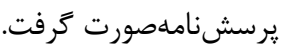
در ادامه ابزار جمع آورى اطلاعات براى يزوهش حساضـــ

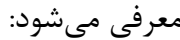

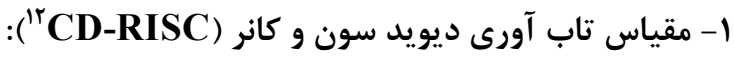

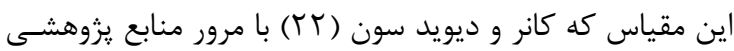

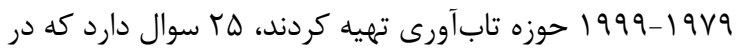

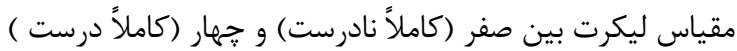

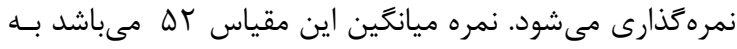

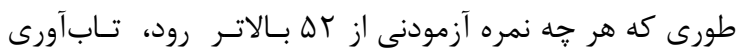

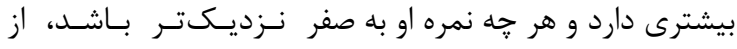

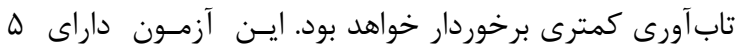

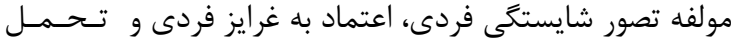

10- Samsung Gear VR Virtual Reality Headset 11- Samsung Galaxy S7

12- Connor-Davidson Resilience Scale (CD-RISC)
متصور بود. درواقع فن آورى واقعيت مجازى مى متواند بـا الـقـــاء

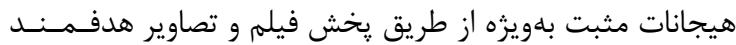

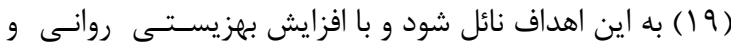

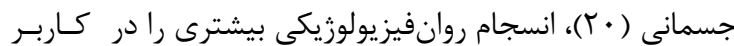

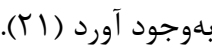

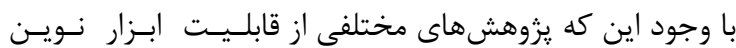

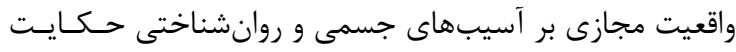

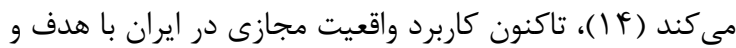

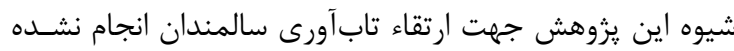

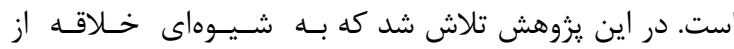

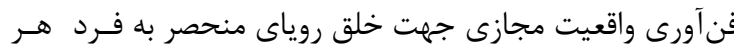

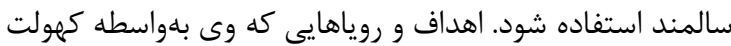

سن و محدوديتهاى زندكى، امكان دستيابى به آن را ندارد.

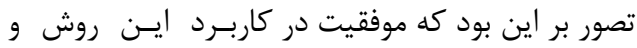

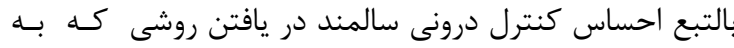

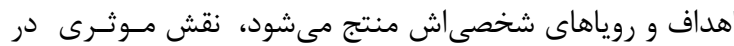

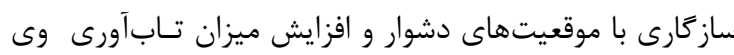

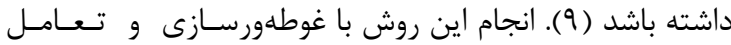

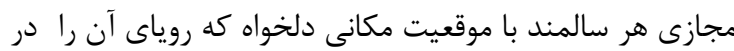

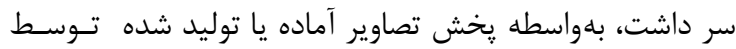

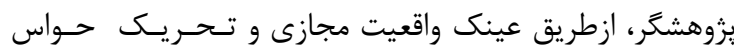

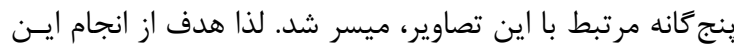

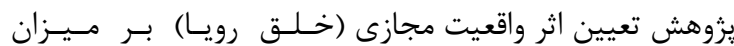

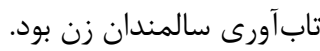

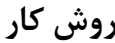

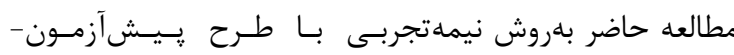

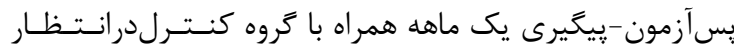

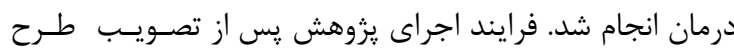

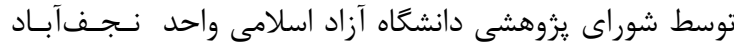

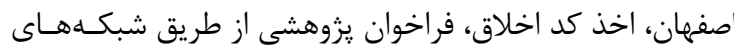

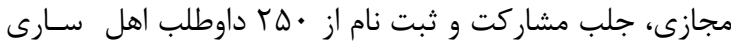

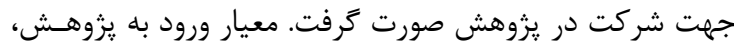

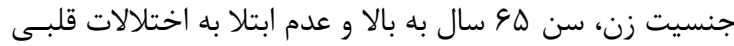

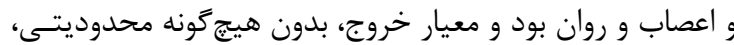

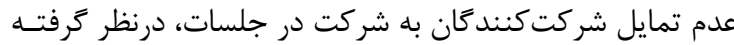

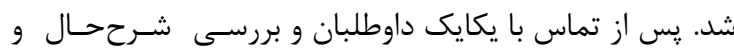

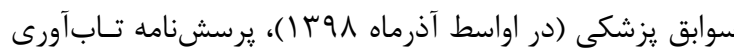

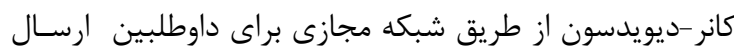

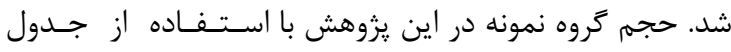

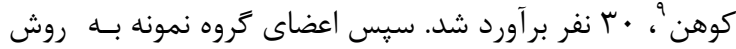

9- Cohen 


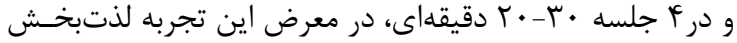

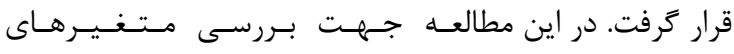
جمعيتشناختى و وابسته، از شاخصهاى آمارى فراوانى، درصد،

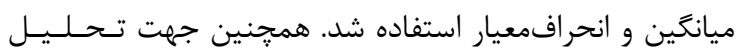

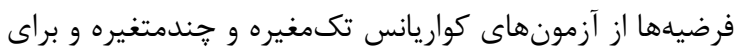

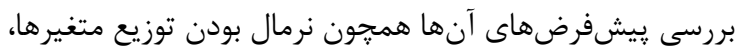

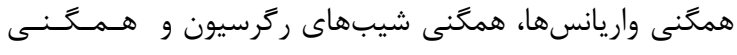

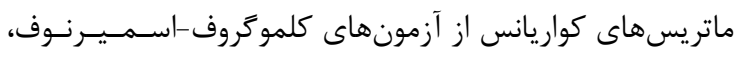

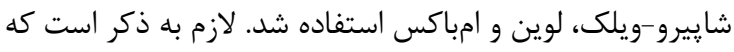

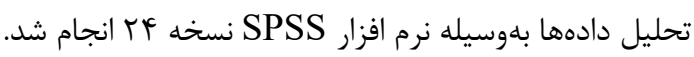

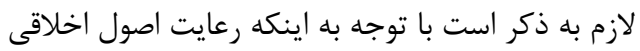

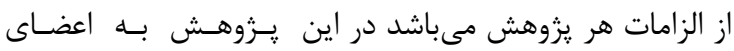

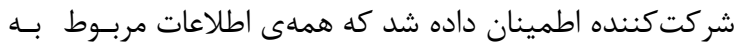

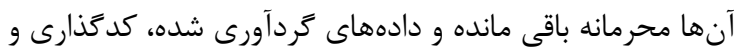

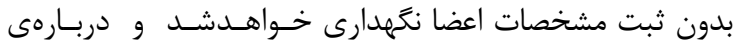

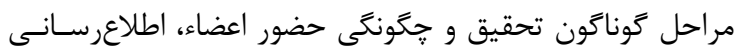

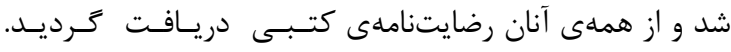

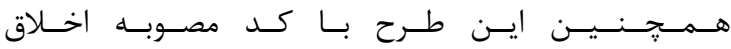

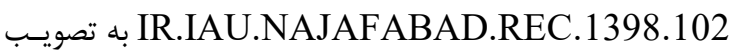

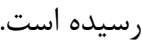

\section{يافتهها}

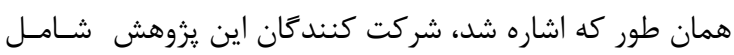

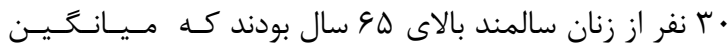

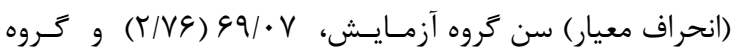
كنترل در انتظار درمان

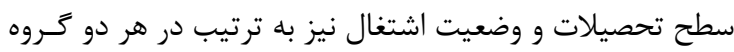

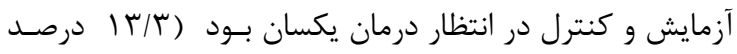

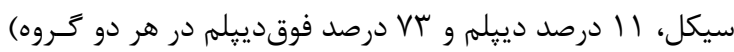

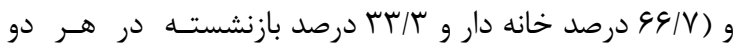

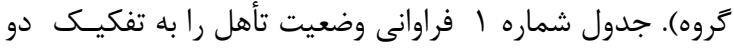

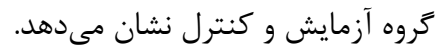

عاطفه منفى، يذيرش مثبت تغيير و روابط ايمـن، كـنـتــرل و تأثيرات معنوى است.

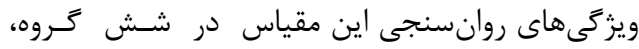

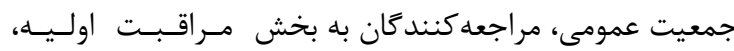

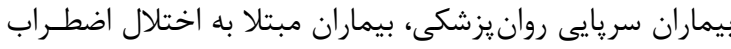

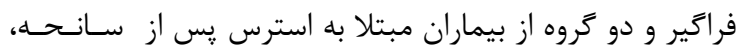

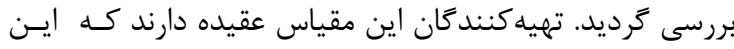

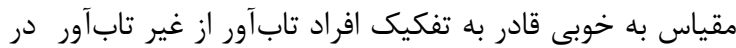

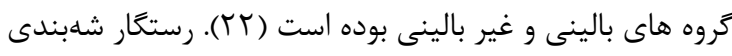

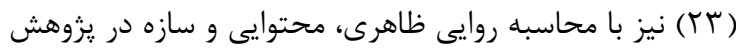

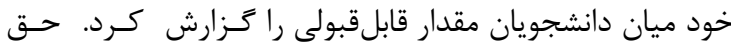

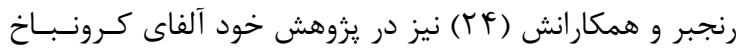

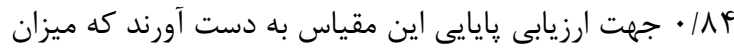
قابل قبولى است. r- يرسشنامه محقق ساختهى اطلاعات جمعيتشناختى

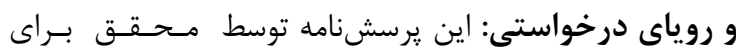

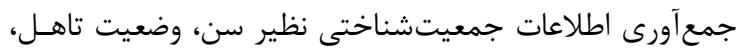

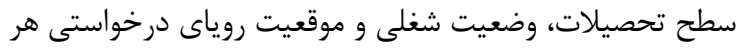
مشاركت كننده تنظيم شد.

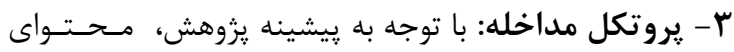

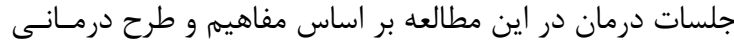
يزوهش لين، لى، لالى، جوزف و كاقلين (ع) (1) بود كه از تصاويـر

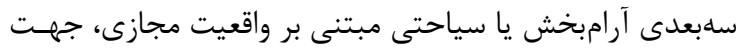

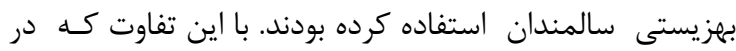

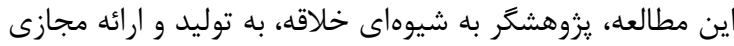

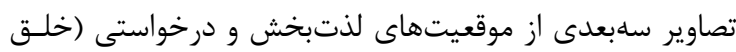

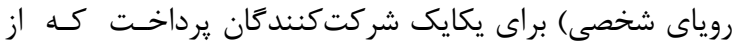

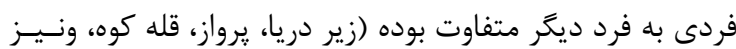

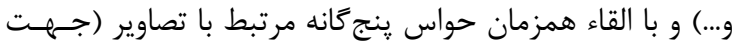

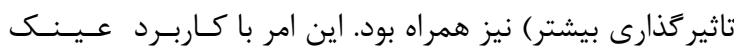
واقعيت مجازى ميسر شد، بهطورى كه هرسالمند، طى يكى مـاه

\section{جدولا: فراوانى و درصد فراوانى وضعيت تأهل}

\begin{tabular}{|c|c|c|c|c|}
\hline \multicolumn{2}{|c|}{ گروه كنترل در انتظار درمان } & \multicolumn{2}{|c|}{ كروه آزمايش } & \multirow{2}{*}{ وضعيت تاهل } \\
\hline درصد فراوانى & فراوانى & درصد فراوانى & فراوانى & \\
\hline G9/V & 1. & $F \& / V$ & V & متأهل \\
\hline א/rו & r & r/r & r & مجرد \\
\hline $1 \pi / \pi$ & $r$ & TS/V & f & بيوه \\
\hline $9 / V$ & 1 & G/V & 1 & مطلقه \\
\hline$\cdot$ & · & $9 / V$ & 1 & بدون پاسخ \\
\hline $1 \ldots$ & 10 & $1 \cdots$ & 10 & كل \\
\hline
\end{tabular}


در جدول شماره ؟، شاخصهاى توصيفى ميانگَيـن و و

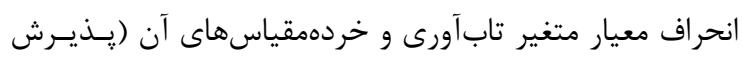

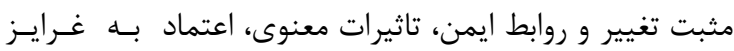

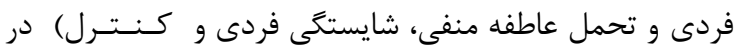

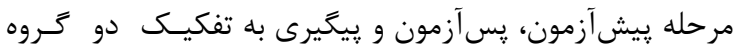

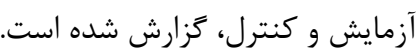

بر اساس نتايج جدول شماره ا، فراوانى وضعيت تأهل در هر دو

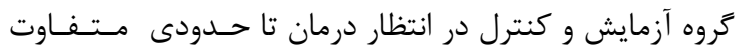

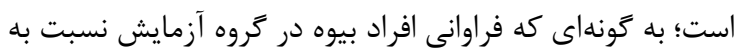

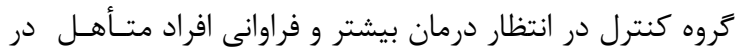

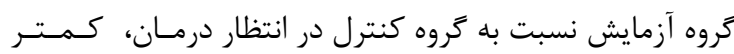
مى باشد.

جدول ז: ميانكَين و انحراف معيار نمرات متغير تاب آورى و خردهمقياسهاى آن به تفكيك مراحل يِيش آزمون و يس آزمون

\begin{tabular}{|c|c|c|c|c|c|c|c|}
\hline \multicolumn{2}{|c|}{ بيخيرى } & \multicolumn{2}{|c|}{ يسآزمون } & \multicolumn{2}{|c|}{ يِشآزمون } & \multirow{2}{*}{ كروه } & \multirow{2}{*}{ متغيرهاى وابسته } \\
\hline انحر اف معيار & ميانگين & انحراف معيار & ميانگين & انحراف معيار & ميانگين & & \\
\hline $1 / T V$ & $\mid r / T$. & $1 / 11$ & سז/rו & $1 / \Delta \Lambda$ & rr/.1 & آزمايش & \multirow{2}{*}{ يذيرش مثبت تغيير و } \\
\hline $1 / 90$ & $1 \cdot / 1 r$ & $1 / V 9$ & س & $1 / \wedge 9$ & 1.1 .9 & كنترل & \\
\hline.$/ 91$ & $\Delta / 1 T$ &.$/ 9 F$ & $\Delta / T$. & $\cdot|\Lambda|$ & $4 / 99$ & آزمايش & \multirow{2}{*}{ تأثيرات معنوى } \\
\hline . /Ar & F/QT &.$/ 91$ & f/94 &.$/ 91$ & $\varphi / \varepsilon$. & كنترل & \\
\hline $1 / \pi$. & $\mid F / \wedge \varphi$ & $1 / \cdot 9$ & $10 / T G$ & $1 / D F$ & $1 \% / 99$ & آزمايش & \multirow{2}{*}{ تحتماد به غرايز فردى و } \\
\hline $1 / \Lambda$. & $\mid r / \Delta r$ & $1 / V 9$ & $1 r / I r$ & $1 / V 9$ & $\mid r / \cdot 9$ & كنترل & \\
\hline $1 / 90$ & IS/A9 & $r / I T$ & IVTr & $1 / 19$ & $\mid f / T$. & آزمايش & \multirow{2}{*}{ شايستكى فردى } \\
\hline $1 / r \Lambda$ & $1 \pi / 94$ & $1 / 95$ & IT/AG & $r / \cdot V$ & $1 \pi / T$. & كنترل & \\
\hline.$/ 91$ & $V / \varphi$. & $\cdot / V \Delta$ & $\wedge$ & $1 / 1 T$ & $9 / 1 \pi$ & آزمايش & \multirow{2}{*}{ كنترل } \\
\hline $1 / \cdot 1$ & $9 / \Lambda$. & $1 / \pi$. & G/DT & $1 / 79$ & r/s & كنترل & \\
\hline$r / \cdot \Lambda$ & $\Delta \varphi / 9 \varphi$ & $r / \wedge q$ & $\Delta N / I T$ & $r / 09$ & FA & آزمايش & \multirow{2}{*}{ نمره كل تابآورى } \\
\hline $1 / V$ & FN/q & $r / F V$ & $F V / F \varphi$ & $1 / 94$ & FV/TG & كنترل & \\
\hline
\end{tabular}

كنترل در انتظار درمان، جهت آزمودن معنادارى تفاوت بين دور دور

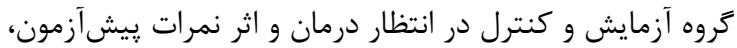
از تحليل كواريانس استفاده شد.

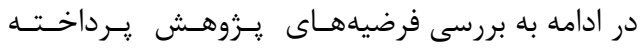

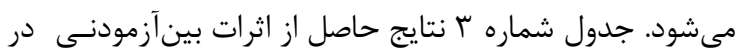

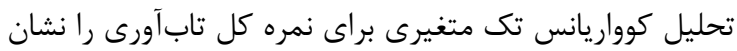

مى دهد.
براساس يافته هاى جدول شماره ז، ميانكين نمره كل تابآورى

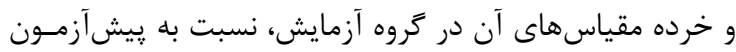

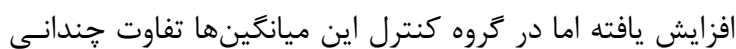

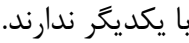
لازم به ذكر است كه پيش از بررسى فرضيهها، نـرمـال

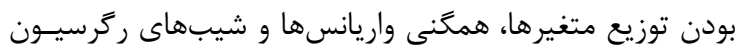

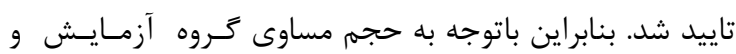

جدول ץ: آزمونهاى اثرات بين آزمودنى در تحليل كوواريانس تكمتغيرى بر نمره كل تابآورى

\begin{tabular}{|c|c|c|c|c|c|c|c|}
\hline آزمون & اندازه اثر & 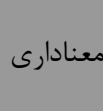 & $\mathrm{F}$ & مجذيانكين & $\mathrm{df}$ & مجذورات & منبع تأثير \\
\hline .1994 & $\cdot / 190$ & .1 .19 & G/DFV & ५ ब/q . & 1 & ५ ब/q . & ثابت \\
\hline - IAGF &.$/ T V T$ & $\% F$ & $1.1 \cdot v \Delta$ & $\Delta \Delta / / q 1$ & 1 & $\Delta \Delta / / q 1$ & ييش آزمون تابآورى \\
\hline \multirow[t]{3}{*}{1} & - /ATV &.$\%$ & $|T A / A F|$ & $V 91 / 909$ & 1 & $V 91 / 909$ & كروه \\
\hline & & & & $\Delta / F M \Lambda$ & $T V$ & IFN/IVG & خطا \\
\hline & & & & & r. & $\Lambda \notin \varepsilon q Y / \ldots$ & كل \\
\hline
\end{tabular}


در ادامه، جدول شماره \& نتايج حاصل از نتايج اثـرات

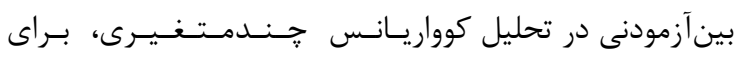
خردهمقياس هاى متغير تابآورى را نشان ميىدهد. دهد.
همانطور كه نتايج جدول شماره ب نشان مسىهــد، اثـر بـيـن

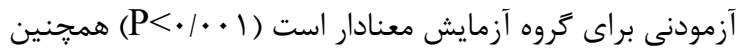

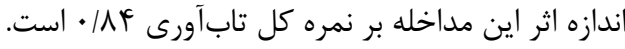

جدول f: آزمونهاى اثرات بين آزمودنى در تحليل كوواريانس جندمتغيرى براى خردهمقياس هاى تابآورى

\begin{tabular}{|c|c|c|c|c|c|c|c|c|}
\hline 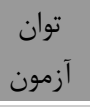 & اندازه اثر & معنادارى & $\mathrm{F}$ & ميذانحَين & df & 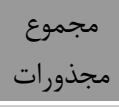 & متغير وابسته & 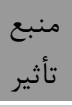 \\
\hline . /99V & $\cdot|\Delta| F$ & $\cdot 1 \cdot$ & TF/MFA & rr/VAS & 1 & rr/VAS & ڤِ & \multirow{5}{*}{ 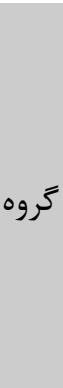 } \\
\hline$\cdot / \& \Delta q$ &.$/ 1 \mathrm{~F}$. & .1 .90 & r/VDq & I/DAT & 1 & I/DAT & يسآزمون تأثيرات معنوى & \\
\hline 1 & $.19 \mathrm{~V}$. & $\cdot 1 \cdot \cdots$ & $F \& / 09 V$ & $F \Delta / F \Delta 1$ & 1 & $F \Delta / F \Delta \mid$ & يسآزمون اعتماد به غرايز فردى و & \\
\hline 1 & $.109 \mathrm{~V}$ & $\cdot 1 \cdot \cdots$ & $r F / 11 \Lambda$ & $1 \cdot 1 / \cdot 10$ & 1 & $1 \cdot N / \cdot 10$ & يسآزمون شايستخى فردى & \\
\hline 1 & $.194 \Delta$ & $\cdot 1 \cdot \cdots$ & fi/v.. & $I N / V \cdot V$ & 1 & $I N / V \cdot V$ & يֶ آزمون كنترل & \\
\hline
\end{tabular}

بيشترين اندازه اثر كاربرد واقعيت مجازى (خلق رويا)، بر مؤلفــه

اعتماد به غرايز فردى و تحمل عاطفه منفى است (AV (Y) •).

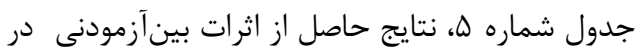

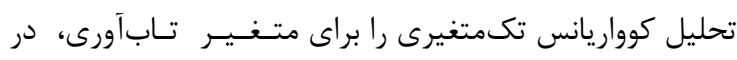
مرحله پِيگيرى نشان مى دهد.
بر اساس جدول شماره \& أ اثر بين آزمودنى براى گَروه

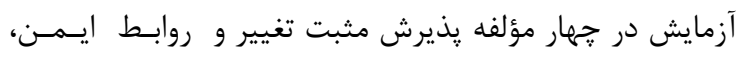

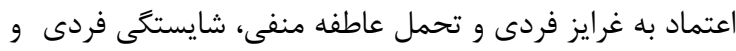

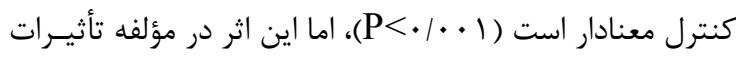

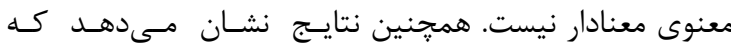

\section{جدول ه: آزمونهاى اثرات بين آزمودنى در تحليل كوواريانس نمره كل تاب آورى در مرحله بِيكيرى}

\begin{tabular}{|c|c|c|c|c|c|c|c|}
\hline توان آزمون & اندازه اثر & معنادارى & $\mathrm{F}$ & مجذانگَين & df & مجموع مجذورات & منبع تأثير \\
\hline $.19 \mu$. & • & $\cdot 1 \cdot \cdot 1$ & IT/VTA & $v \cdot / 1 \cdot 1$ & 1 & $v \cdot / 1 \cdot 1$ & ثابت \\
\hline . IDFE &.$/ 1 \mathrm{FV}$ & $\cdot 1 \cdot 4$ & F/ArA & TQ/DFG & 1 & TD/DFG & ييشآزمون تابآورى \\
\hline 1 & •/VT. & $\cdot 1 \cdots$ & $V T / I I T$ & $F \cdot r / V I$. & 1 & $F \cdot r / V I$. & كروه \\
\hline
\end{tabular}

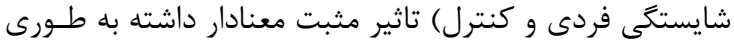

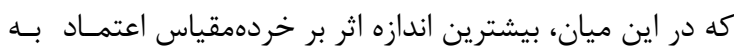

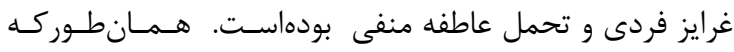

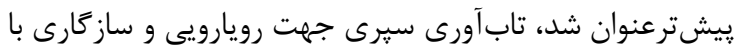

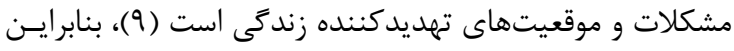

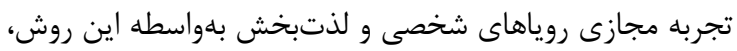

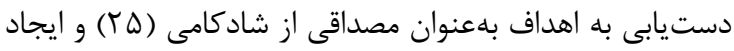

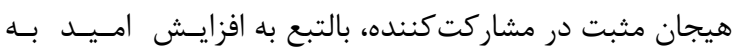

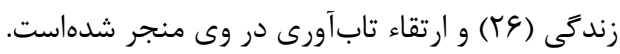

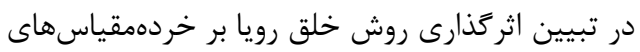

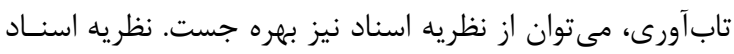

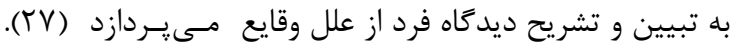
موفقيت در يافتن روشى كه به اهداف و روياهاى شخصى منتـج دئج

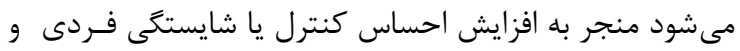

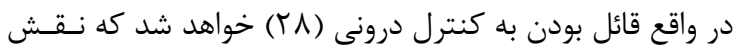

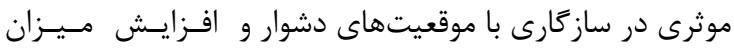

بر اساس نتايج جدول شماره ه، اثر بين آزمودنى بـراى گَرـروه

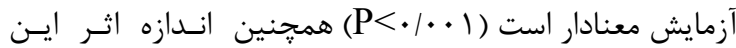

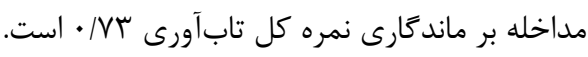

بحث و نتيجهَيرى

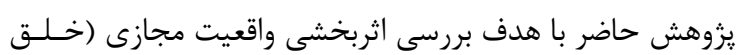

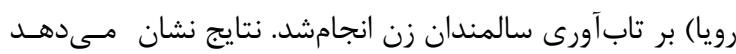

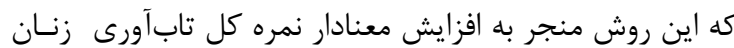

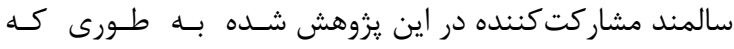

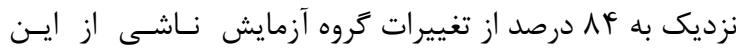

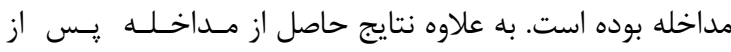
كذشت يك ماه نيز پايدار ماندهاست.

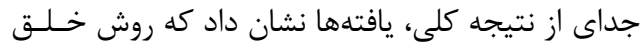

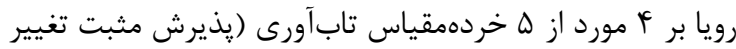

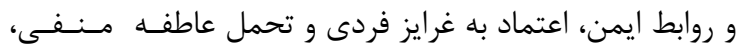




\section{تشكر و قدردانى}

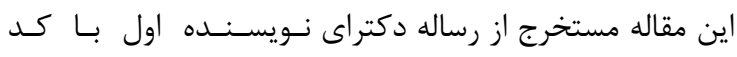

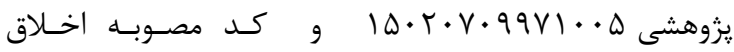
IR.IAU.NAJAFABAD.REC.1398.102 مى مبـاشـد. در پايان از سالمندان ارزشمندى كه با همكارىشان در بيشبـرد

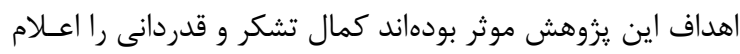

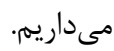

تاب آورى دارد (9). از طرفى افزايش ميزان شادكامى و هيـجـان

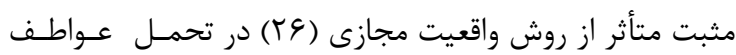

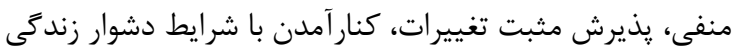

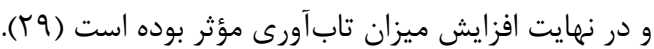

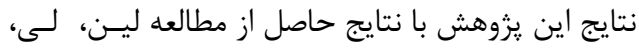

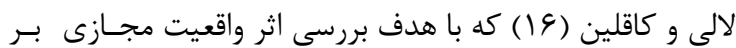

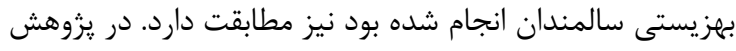

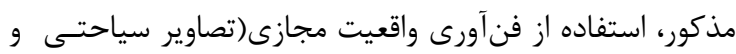

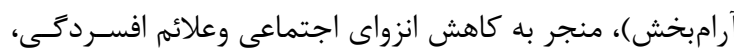

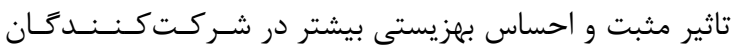

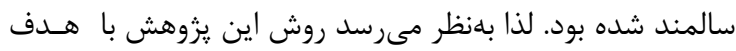

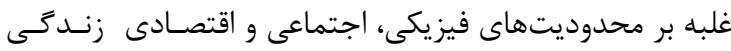

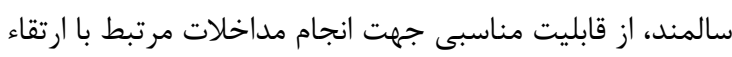

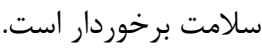

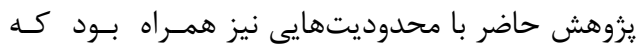

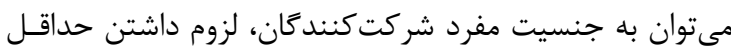

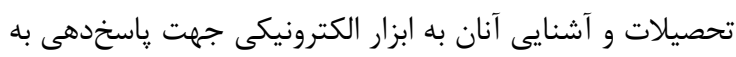

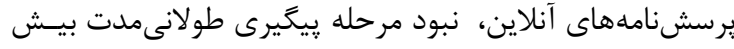

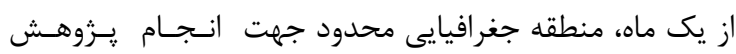

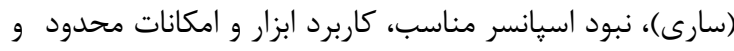

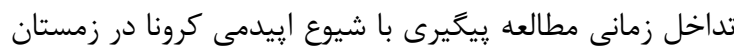

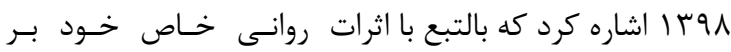
شركت كنندكان همراه بود.

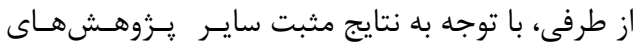

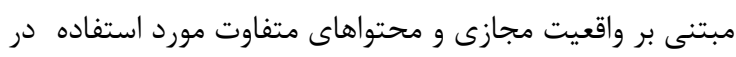

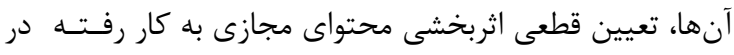

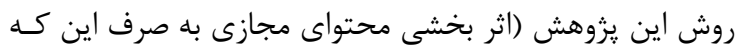

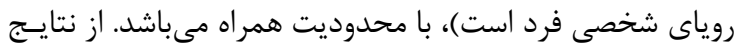

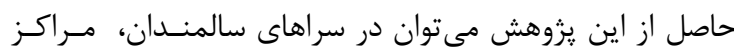

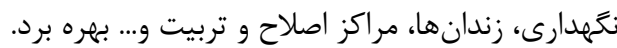

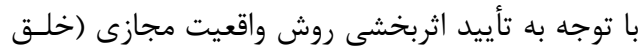

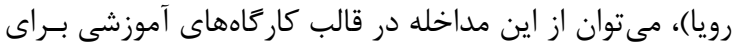

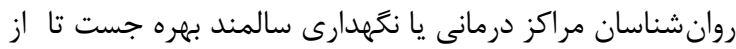

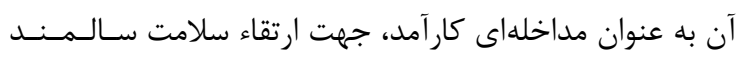

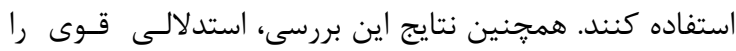

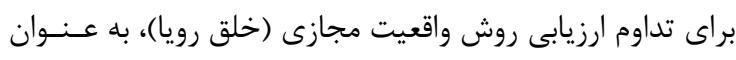

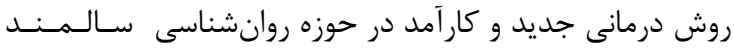

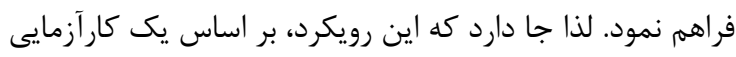

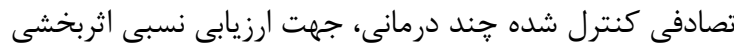

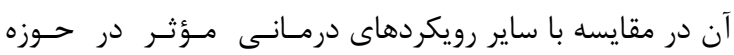

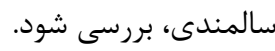




\section{References}

1- Stuart-Hamilton, Ian. The psychology of ageing: An introduction: Jessica Kingsley Publishers; 2012. 2- Harrefors C, Savenstedt S, \& Axelsson Kavin. Elderly People's Perceptions of How they want to be cared for: An interview study with healthy elderly couples in Northern Sweden. J Caring Sci. 2009; 23: 353-360.

3- Khaje-Bishak Y, Payahoo L, Pourghasem B, \& Asghari Jafarabadi M. .Assessing the quality of life in elderly people and related factors in Tabriz, Iran. J Caring Sci. 2014; 1, 3(4): 257-263.

4- Khodabakhshi-koolaee, A. The comparison of health literacy and lifestyle among retired and homemaker older adults' women. JH letracy. 2016; 1(3): 155-163.

5- Kheirollahi F, Sharifshad F, Sarraf P , Mohammadsalehi N \& Mohammad beigi A. Evaluation the correlation between general health status and happiness with family childnumber in high school girls. The J Urmia nurs midwifery fac. 2017; 14 (11): 934-41 [Persian].

6- Sumngern C. H, Azeredo Z, Sabgranon R, Sun $\mathrm{N}, \&$ Maos E. Happiness among the elderly in communities: A study in senior clubs of Chonburi province Thailand. Japan Journal of nursing science. 2010; 7: 47-54.

7- Lim C , \& R D Putnam. "Religion, social networks, and life satisfaction. American Sociological Review. 2010; 75(6): 914-933.

8- Darvishpoor kakhki A, Abed saeedi. Factors related to health related quality of life(HRQOL) of elderly people in Tehran. The journal of nursing and midwifery. 2013; 23(82):8-16. [Persian].

9- Faal kalkhoran L, Bahrami H, Farokhi N, Zeraati H, Tarahomi M. Comparing anxiety, Depression and sexual life satisfaction in two groups of fertile and infertile women in Tehran. Journal of reproduction and infertility.2011;2(47): 157-163. [Persian].

10- Oginska-Bulik, N, \& Zadworna-Cieslak, M. The role of resiliency and coping strategies in occurrence of positive changes in medical rescue workers. International emergency nursing. 2018;39:40-45.

11- Oshio, A , Taku, K, Hirano, M , \& Saeed, G. Resilience and Big Five personality traits: A metaanalysis. Personality and Individual Differences. 2018; 127: 54-60.

12- Schure. MB , Odden, M \&\& Goins, RT.The association of resilience with mental and physical health among older American Indians: the Native Elder Care Study. Am Indian Alsk Native Ment Health Res. 2013; 20(2): 27-41.

13- Lin, Cheng-Shih, Jeng, Mei-Yuan ,\& Yeh,TsuMing. The Elderly Perceived Meanings and Values of Virtual Reality Leisure Activities: A Means-End Chain Approach. International Journal of Environmental Research and Public Health. 2018; 15 (663), 1-13.

14- Ali akbari M, Alipoor A, Ebrahimi moghadam $\mathrm{H}$, Fakerti M. The effect of virtual reality (VR) on psychological disorders in cancer cases. Journal of Military caring science. 2017; 4(1):49-57.[Persian].
15- Baltes, PB , Staudinger, UM , \& Lindenberger, U. Lifespan psychology: theory and application to intellectual functioning. Annu Rev Psychol.1999; 50(1):471-507.

16- Lin, Charles Xueyang, lee,Chaiwoo , lally, Dennis ,\& coghlin, Joseph F. Impact of Virtual Reality (VR) Experience on Older Adults' WellBeing. 2018;LNCS 10927, 89-100.

17- Lin, Cheng-Shih, Jeng, Mei-Yuan ,\& Yeh,TsuMing.The Elderly Perceived Meanings and Values of Virtual Reality Leisure Activities: A Means-End Chain Approach. International Journal of Environmental Research and Public Health.2018; 15 (663):1-13.

18- Koohi habibi S.The role of virtual reality systems in improving disabilities in old age. Studies of psychology and educational science. 1394;(1): 27 40.[Persian].

19- Gerrard-Hess, A , Spies,k \& Hesse, F. W. Experimental inductions of emotional states and their effectiveness. A review. British Journal Of Psychology.1994; 85: 57-78.

20- Chesney MA, Darbes LA, Hoerster K, \& Taylor JM, Chambers DB \& Anderson DE. Positive emotions:Exploring the other hemisphere in behavioral medicine. Inter J Behavioral Med. 2005; 12 (2): $50-8$

21- McCraty, R \& Rees, R. The central role of the heart in generating and sustaining positive emotions. In C. R. Snyder \& S. Lopez (Eds). Oxford handbook of positive psychology , 2nd ed. New York: Oxford Univ Press: 2009: 527-548.

22- Connor, K. M , \& Davidson, J. R. T. Development of new resilience scale: the connor- Davidon, Resilience scale (CD-RISC). Depression and. Anvety. $2003 ; 18(2): 76-82$.

23- Rastegar Shahbandi Sh. Prediction of Responsibility based on Spiritual Intelligence, Considering intermediary Role of Resiliency .Journal of sociology of education. 2018; 9(9):79-94.[Persian].

24- Hagh ranjbar F, Kakavand A.R, Borjali A, Bermas H. Resiliency and life quality in mothers of children with mental retardation. Journal of health psychology. 2011; 1(1).177-187. [Persian].

25- Snyder, C. R. Hope theory: Rainbows in the mind, psychological. Psychological Inquiry. 2002; 13: 249- 275.

26- Villani D, Riva F , Riva G. New technologies for relaxation: The role of presence. International journal of Stress Manage. 2007; 14(3):260-74. DOL:10.1037/1072-5245.14.3.260.

27- WentzeL KR, Battle A, Russell SL, Looney LB. Social supports from teachers and peers as predictors of academic and social motivation. Contempt Educ Psychol. 2010; 35(3):193-202.

28- Brewin CR. Understanding cognitive behaviour therapy: A retrieval completion account. Behav Res Ther. 2006; 44(6): 765-784.

29- Zuatra, A., Johnson, J. L, Davis, M. Positive Affect as a source of resilience for women in chronic pain. Journal of consulting and clinical psychology. 2005; 73:212-220. 